\title{
A desnecessidade do trabalho entre pescadores artesanais'
}

\section{Resumo}

As relações socioculturais e econômicas, entre alguns grupos de pescadores artesanais, não colocam como entes antagônicos trabalho e tempo livre. Do contrário, tais relações celebram aproximações entre saber-fazer pesqueiro, lazer e vida, formando e conformando um todo societário. Inseridos nesse quadro, estão os pescadores artesanais do mar-de-fora da praia de Suape, no município do Cabo de Santo Agostinho, litoral sul de Pernambuco, distante 50 km de Recife. Este artigo busca desvelar a mencionada moral do trabalho e do tempo livre no fazer cotidiano de pescadores dessa Praia, com base na pesquisa etnográfica e na história de vida de 13 pescadores. No geral, identificou-se que há uma moral do trabalho que se confunde à moral do tempo livre, pois o cerceamento de uma delas representa limites à outra. Assim, para esses homens, definir o que é um ser liberto ou cativo liga-se ao encontro indissociável, em termos práticos e simbólicos, entre as referidas morais, o que é essencial para classificar o fazer-se pescador artesanal em seu sentido pleno fundamentado na desnecessidade do trabalho.

Palavras-chave: Moral do Trabalho. Desnecessidade do Trabalho. Sociologia da Pesca. Sociologia Rural. Pescador Artesanal.

\footnotetext{
${ }^{1}$ Este texto é uma síntese de um dos capítulos de minha tese de doutoramento (RAMALHO, 2007), que foi financiada pelo CNPq, por meio de uma bolsa, e que contou com a orientação do Prof. Dr. Fernando Antonio Lourenço (IFCH-Unicamp).

* Universidade Federal Rural de Pernambuco (Brasil)
} 


\section{The dispensable character of work among artisanal fishermen}

\section{Abstract}

Socio-cultural and economic relations among some groups of artisanal fishermen do not take work and free time as antagonistic entities. Conversely, such relationships celebrate similarities between fishing skills, leisure and life, which configure a societal whole. Artisanal fishermen from mar-de-fora in the beach of Suape, district of Cabo de Santo Agostinho, southern coast of Pernambuco, distant $50 \mathrm{~km}$ from Recife. This article seeks to reveal the work and free time ethic entailed in the daily tasks of fishermen in this beach, based on ethnographic research and life history of 13 fishermen. It was observed a work ethic that is confused with the morality of free time, since a restriction on one of them implies limits to the other. Therefore, for these men, being defined as free man or as captive is referred to the inseparable connection, in both practical and symbolic terms, between these two moralities, what is essential for fully qualifying as an artisan fisherman based on the dispensable character of work.

Keywords: Work ethic. Dispensable character of work. Sociology of fishery. Rural Sociology. Artisanal fishermen. 


\section{Apresentação}

Somos o resultado de tanta gente, de tanta história, tão grandes sonhos que vão passando de pessoa a pessoa, que nunca estaremos sós (Valter Hugo Mãe, O filho de mil homens)

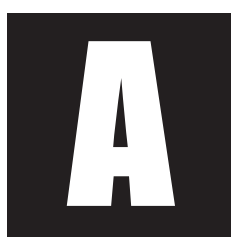

s relações socioculturais e econômicas, em alguns grupos de pescadores artesanais e camponeses, não colocaram como entes antagônicos trabalho e tempo livre. Ao contrário, tais relações celebram aproximações e indissolubilidades entre saber-fazer pesqueiro, lazer e vida, formando e conformando um todo societário. Aspectos esses que estão contidos na forma de ser e fazer-se dos pescadores artesanais aqui estudados, cujas características socioculturais e econômicas de vida não assumem maneiras de resistências políticas e/ou de mobilização social. Dessa maneira, não se está afirmando que os pescadores artesanais negam os marcos do capital (aliás, isso nem é uma questão mencionada pelos pescadores), mas apenas que tais sujeitos sociais possuem maneiras de lidar com o tempo de trabaIho e o de lazer oriundas de um modo de vida fundamentado em relações materiais e simbólicas típicas de grupos sociais que se apoiam em uma fecunda contra-racionalidade (Brandão, 2007, p. 42), distinta da racionalidade da economia moderna, em que, de acordo com a lógica existencial dos grupos tradicionais, a própria economia é uma das muitas dimensões de uma cultura (idem, p. 55), que cruza valores morais, estéticos e sociais não similares aos do mundo dos negócios.

Na realidade, tem-se uma moral do trabalho que se confunde à moral do tempo livre. Vida e trabalho são momentos repletos de reciprocida- 
des e complementaridade, e, assim, não são compreendidos em oposição por muitas comunidades que sobrevivem da pesca, seja na necessidade de trabalhar, seja na desnecessidade do trabalho. Inseridos nesse quadro societário, estão os pescadores artesanais do mar-de-fora ${ }^{2}$ da praia de Suape, no município do Cabo de Santo Agostinho, litoral sul de Pernambuco, distante $50 \mathrm{~km}$ de Recife.

Este artigo focaliza a mencionada moral do trabalho e do tempo livre no fazer cotidiano de pescadores da Praia de Suape. Assim, efetivaram-se comparações com outras situações mencionadas em textos acadêmicos sobre outras realidades nacional e internacional. A pesquisa de campo estendeu-se de dezembro de 2004 a dezembro de 2006 e se fundamentou na etnografia, história de vida de treze pescadores (entrevistados inúmeras vezes), observação participante (embarquei, inclusive, com os pescadores para o mar alto) e direta e a realização de vários outros colóquios, os quais formaram o acervo empírico e a base da análise teórica deste escrito.

Cabe destacar que, no momento em que se encerrou a aludida pesquisa etnográfica, estavam tendo início as obras de construção da Refinaria Abreu e Lima e de ampliação de trechos do Complexo Portuário de Suape. Portanto, os impactos socioambientais oriundos dessas ações não serão alvo da presente análise.

\footnotetext{
${ }^{2}$ Os termos mar-de-dentro e mar-de-fora são definidos pelos próprios pescadores de Suape, que os empregam para diferenciar a pesca feita antes e depois da arrebentação do mar, dos arrecifes. Quem passa da arrebentação é um pescador de mar-de-fora e quem pesca em rios, estuários e praia, e não chega a ultrapassar a barreira natural, trabalha no mar-de-dentro. O primeiro é pescador marítimo, que utiliza barco motorizado para trabalhar no Oceano Atlântico.
} 


\section{Mundo Produtivo e Mundo da Vida: o casamento da condição liberta}

Ao estabelecer comparações relativas a outros grupos de trabalhadores da localidade em que vive (engenhos, fábricas, comércio, casas de veraneio e setor da construção civil) no litoral pernambucano, o pescador de Suape percebe-se enquanto alguém que é portador de uma liberdade incomum, especialmente por dispor diretamente do uso do seu tempo de trabalho e lazer. Isto é, tal liberdade pode ser entendida como uma maneira singular de gestão do seu tempo de trabalho e de lazer, fato similar ao que encontrou Antonio Carlos Diegues $(2001 ; 2004)$ quando analisou a ideia de liberdade dos pescadores, de populações tradicionais, ao relacioná-la às formas de gerir os usos dos recursos naturais pesqueiros, de acordo com as dinâmicas socioculturais e econômicas das próprias comunidades locais.

O pescador de Suape, para diferenciar a condição de liberto que acredita possuir, elaborou alguns termos como antíteses à sua situação. Por exemplo, estar obrigado, ser sujeito e cativo são elementos desabonadores e antípodas à condição liberta, pois significam a perda da autonomia do trabalho, do seu produto final e de seu lazer. Na pesca, essas categorias encontram-se e, desse modo, não ocorre uma separação entre elas, sendo, portanto, sinônimos. No geral, vão representar o contexto de degredo da possibilidade de ser livre, de ter autonomia, de ser um artista do mar e, portanto, um verdadeiro pescador artesanal, fatores clarificados pelas transcrições abaixo das entrevistas.

Entrevistador: Mas o que é o cara obrigado?

O obrigado é o... eu tenho, aqui, essas redes. Vamos supor, eu dou a outro pra outro ir pescar, e ele vai ter que vender o peixe pra mim. O cabra fica preso a outro. O cabra tem o peixe dele e tem que vender àquela pessoa. Ele fica cativo àquela pessoa. Agora, eu pego o peixe e vendo a quem quero. Eu não sou cativo a ninguém. 
Sociologias, Porto Alegre, ano 17, no 38, jan/abr 2015, p. 192-220

Entrevistador: Mesmo quando não tem o barco e a rede, o pescador se sente livre?

Ele não tendo o barco e a rede ele é livre, porque ele chega [do mar], botou o peixe na mão e vai embora. Acabou-se. Pode deixar a parte do barco e levar a sua, que ninguém vai tar reclamando (seu Neneu, pescador mestre ${ }^{3}, 67$ anos).

Entrevistador: o que é ser uma pessoa cativa?

Cativo é você ser manobrado. Já eu não sou cativo. Não trabalho pra ninguém. Eu pesco pra mim. Pesco o que quero e vou o dia que quero com os meus companheiros de trabalho. Eu sou liberto. Agora tem pescador que pesca pras empresas de pesca. Então, ele é empregado e ele tem aquela obrigação. São sujeitos. São cativos.

Entrevistador: Mas e o artista da pesca?

O artista da pesca não tá obrigado a ninguém (seu Gidinha, pescador mestre, 70 anos).

A partir dos depoimentos acima, obrigação é quando o cabra fica preso a outro (seu Neneu), asfixiando suas possibilidades de escolhas sobre o que fazer com seu trabalho, o fruto dele e, principalmente, com sua vida. É pelo trabalho que o ser humano, para o pescador, é considerado liberto ou sujeito, porque cativo é você ser manobrado. Então, ele é empregado e tem aquela obrigação. São sujeitos. São cativos (seu Gidinha) em suas vidas. Diante dessa constatação da insujeição, do não cativeiro, da não obrigação, diz-se que eu sou liberto (seu Gidinha) e eu não sou cativo a ninguém (seu Neneu) enquanto homem, na qualidade de pescador, já que as forças vitais, as utilidades humanas não estão subjugadas diretamente por outrem, quando eles continuam a estabelecer a aludida comparação.

\footnotetext{
${ }^{3}$ Pescador mais hábil no mar, o que comanda a embarcação e sabe marcar as rotas no oceano e suas áreas mais piscosas. Receber o atributo de mestre resulta de uma autoridade e reconhecimento que determinado pescador conquista junto aos demais profissionais de pescaria, particularmente por conta de sua grande habilidade para lidar com os aspectos náuticos, pesqueiros e de coordenação dos homens no barco motorizado (o bote).
} 
Até mesmo aqueles pescadores que não detêm os meios de trabalho consideram-se livres e, principalmente, se sentem assim, devido à própria lógica de organização voluntária do trabalho. Dos pescadores entrevistados, constatou-se que a metade detém barco e rede, 38\% pescam em barcos de irmãos ou pai, $8 \%$ no de amigos/compadres e apenas um caso trabalha em barco de terceiros (um não pescador). Mesmo nessa última situação, não há uma relação estritamente capitalista, de exploração da força de trabalho ${ }^{4}$.

Para os suapenses, esses instrumentos são, em larga medida, bens comuns de uso da tripulação mantidos através do quinhão (do barco e da rede), que funciona como uma espécie de fundo de manutenção dos instrumentos de trabalho, depois de retirada a parte que compete à tripulação numa divisão igualitária.

Algo similar ao fundo de manutenção campesino descrito por Eric Wolf (1970):

\begin{abstract}
Mais da metade do total produzido era então recolhida adiantadamente para semear e alimentar. Esse montante não pode ser considerado como excedente, uma vez que se destinava à manutenção dos instrumentos de produção. O cultivador tinha que economizar tempo e esforços para serem despendidos no reparo de suas ferramentas, para afiar suas facas, vedar seu depósito de armazenagem, para cercar seu curral, para colocar ferraduras em seus animais de trabalho e talvez até mesmo para construir um espantalho que manteria os pássaros mais atrevidos fora de seus campos. Além disso, ele devia consertar várias coisas, tais como roupas quando elas rasgavam. Os gastos necessários para a restauração desse equipamento mínimo, tanto para a produção como para o consumo, eram o seu fundo de manutenção [grifo do autor] (Idem, p. 18-19).
\end{abstract}

\footnotetext{
${ }^{4} \mathrm{O}$ único caso relativo à posse de terceiros refere-se a um médico, que deixava seu barco e rede sob os cuidados de um mestre, desde que este mantivesse o barco bem conservado para quando ele fosse à localidade com o objetivo de veranear e realizar pescarias. Nessa situação, não há uma extração do sobretrabalho em benefício do médico.
} 
No quinhão, se pescarem três homens, divide-se o produto final em cinco partes (a dos homens, uma da rede e outra do barco). Quando o mestre não possui embarcação, a parte do quinhão da rede é dele, pois essa armadilha fica sob seus cuidados e reparo, e o quinhão do barco é do proprietário (um fundo de manutenção de ambos). O proprietário ou o mestre é o responsável pelo repasse do produto a um intermediário, normalmente parentes ou compadres. Quando os pescadores vendem a produção, o fazem na localidade ou feira próxima situada na sede do município. O quinhão possibilita a existência de dois fenômenos: (1) firma um processo mais igualitário entre os trabalhadores pesqueiros, que os tornam parceiros, sócios, companheiros no mesmo barco e, literalmente, na batalha pela sobrevivência (Ramalho, 2006, p. 102); e (2), principalmente, refuta a dinâmica de acumulação de capital na localidade por parte dos pescadores, já que prende o ganho a um modo antagônico à expansão e domínio do capital em termos diretos.

Como se nota, não se está afirmando, do ponto de vista sociológico, que tais sujeitos são autônomos, pois os pescadores integram as camadas populares de nossa sociedade e, assim sendo, possuem uma pequena incorporação dos capitais impessoais mais importantes da sociedade moderna, capital econômico e capital cultural (Souza, 2010, p. 327), haja vista que mais de $50 \%$ dos entrevistados sabem, no máximo, escrever o próprio nome e $83 \%$ dependem de atravessadores para comercializarem parte considerável de seus pescados (peixes, crustáceos, etc.).

Isso mostra que a feitura de um pescador deve-se à própria feitura da sociedade a qual integra e ocupa papel subordinado na divisão social e nos ganhos do trabalho, como destacou Eric Wolf em relação aos camponeses. Para Wolf (2003, p. 121), ser camponês é uma relação estrutural também. Sem dúvida, o que caracteriza toda classe trabalhadora é a sua 'inclusão subordinada' no processo de acumulação do capitalismo em todas suas fases históricas (Souza, 2010, p. 52). 
Um fator importante para a referida ideia de autonomia dos pescadores vincula-se à reprodução de sua sociedade do trabalho. A sociedade do trabalho dos pescadores incorpora os meios de produção como integrantes da vida do sistema de parceria, da companha. Em resumo, o instrumento de trabalho ainda está fundindo ao trabalho vivo, tão incluído no domínio deste último que, na realidade, não circula (Marx, 1991, p. 101) não produz capital o suficiente para criar capitalistas pesqueiros ${ }^{5}$.

O fenômeno da sociedade do trabalho foi problematizado por Rosyan Britto entre pescadores de Arraial do Cabo, RJ, na lógica da companha (ou campanha):

[...] nota-se que o cálculo dessa repartição do produto reedita a noção de sociedade no trabalho, anteriormente mencionada, indicando que os instrumentos de trabalho estão de tal modo integrados ao corpo social da campanha e da pescaria que acabam se confundindo com os próprios camaradas, adquirindo eles próprios, por extensão, os mesmos "direitos", participando juntos de sua reprodução social [grifos da autora] (Britto, 1999, p. 125).

Ademais, por ter direito à parte da produção final que lhes cabe, qualquer pescador pode levar a sua, que ninguém vai tá reclamando (seu Neneu) por ser um direito coletivo, certo ethos corporativo; e isso vai criar nesses homens o sentimento de que são trabalhadores e produtores não submetidos à obrigação, à sujeição ou ao cativeiro. Há, de fato, um corpo social integrado, que se projeta sobre o mar para existir, como maior liberdade diante de outros sujeitos populares já destacados (canavieiros, caseiros, pedreiros, etc.). Somando-se a isso, está a situação de que o êxito na pesca (uma boa pescaria) é a vitória de todos, bem como o seu fracasso é socializado também.

\footnotetext{
${ }^{5}$ Não está se afirmando que alguns comerciantes e empresas deixem de extrair lucros com a venda da produção local, pois os pescadores estão inseridos numa sociedade de classes e, portanto, nos marcos de domínio do capital.
} 
Sociologias, Porto Alegre, ano 17, no 38, jan/abr 2015, p. 192-220

A perspectiva da liberdade fundamenta-se, dentre outros ingredientes, no sistema de parceria regulador e organizador da estruturação do trabalho pesqueiro artesanal no mar e no estuário. A parceria forja a coesão entre as pessoas embarcadas, fazendo-as perceber, na qualidade de companheiros de uma mesma viagem, que dividem suas desventuras e sucessos, agruras e felicidades, sorte e azar.

Compartilham esses momentos, a venda dos pescados e os ganhos do seu processo de captura. Portanto, uma boa pescaria é boa para todos que nela estão; já o insucesso acaba tendo reflexo direto em todos, porque a pesca é a equipe, é o conjunto de seus trabalhadores envolvidos (Ramalho, 2006, p. 100).

Acresce-se a isso o fato de que os donos dos instrumentos de trabaIho são os mestres e a base da parceria (da companha) é sua família, compadres e amigos de longas datas, onde o peso da dignidade profissional de todos é algo elementar para o bom convívio e existência dessa sociedade e a razão de ser do sentimento de corporação. A exploração é condição indigna a quem a praticaria entre os pescadores suapenses e não a quem sofre. Portanto, não se tem aqui uma separação entre capitalista (donos dos instrumentos de produção e do capital) e os trabalhadores (vendedores da força de trabalho e/ou trabalho subsumido pelo capital), tendo em vista que a pequena acumulação nunca permitiu sair, por exemplo, um empresário da pesca oriundo dessas unidades produtivas, por conta, dentre outras coisas, da existência do quinhão, da organização social do trabalho. Acima de tudo, a companha é um processo de organização do trabalho voluntário, sem assalariamento e vinculado, sobremaneira, aos laços familiares e de compadrio, inexistindo, assim, a oposição direta entre capital e trabalho (Ramalho, 2012, p. 9, grifo do autor).

Tal lógica "tradicionalista", de alguns grupos sociais, formou, para Max Weber, uma "barreira" cultural ao incremento da cultura econômica mais "moderna" do capitalismo sobre o trabalho. 
Eis um exemplo justamente daquela atitude que deve ser chamada de "tradicionalismo": o ser humano não quer "por natureza" ganhar dinheiro e sempre mais dinheiro, mas simplesmente viver, viver de modo como está habituado a viver e ganhar o necessário para tanto. Onde quer que o capitalismo [moderno] tenha dado início à sua obra de incrementar a "produtividade" do trabalho humano pelo aumento de sua intensidade, ele se chocou com a resistência infinitamente tenaz e obstinada desse Leitmotiv do trabalho na economia pré-capitalista, e choca-se ainda hoje por toda parte, tanto mais quanto mais "atrasada" (do ponto de vista capitalista) é mão-de-obra da qual se vê depender (Weber, 2004, p. 53, grifo do autor).

De fato, ao deixarmo-nos iluminar pela abordagem de Weber, transcrita acima, acerca do tradicionalismo, percebe-se uma racionalidade capitalista [moderna] do trabalho, que se choca ainda hoje com a contra-racionalidade dos pescadores artesanais, pois esta quer viver de modo como está habituado a viver e ganhar o necessário para tanto (Weber, 2004, p. 53), de acordo com o seu fenômeno da conduta de vida moral (idem, p. 88, grifo do autor) presente em seu trabalho artesanal.

No caso da pesca artesanal praticada no mar-alto de Suape, há uma mediação social peculiar, uma forma de totalidade parcial (da pesca) que dialoga com a totalidade totalizante do capital, conferindo-lhe particularidades. Evidentemente que isso não faz com que os pescadores da aludida localidade estejam imunes ao processo capitalista de produção e que deixem de estar subordinados à força do capital, particularmente de modo indireto com a venda dos pescados. Apenas, tudo isso (mediação particular oriunda da cultura do trabalho pesqueiro e o processo totalizante do capital) se conforma singularmente, por conta das questões aí presentes, inclusive da capacidade de resistência (sutil e não política), vinculadas à lógica corporativa dos pescadores (Ramalho, 2007). Contudo, cabe frisar que em muitas regiões o processo capitalista subordinou o trabalho 
tradicional pesqueiro em seu favor, ao inserir formas de apropriação do sobretrabalho diretamente com o assalariamento, ora no Brasil (Mello, 1985; Pessanha, 2003), ora em outras partes do mundo (Bidet, 1974; Gac, 2011; Boivin; Rosato, 2011).

Ademais, formas societárias tradicionais - ou, segundo Weber (2006), condutas morais do trabalho típicas das economias pré-capitalistas - não devem ser entendidas, mecanicamente, enquanto sinônimo de liberdade, já que, por exemplo, o trabalho livre, voluntário, é algo exclusivo do capitalismo moderno ocidental, inexistindo antes.

Indo em linha de pensamento que guarda semelhanças com os aspectos ressaltados acima, é interessante mencionar que:

Em relação às sociedades definidas como "tradicionais" na segunda metade do século XIX, o capitalismo apresenta-se como libertador - ou seja, como favorável à realização das promessas de autonomia e autorrealização que o lluminismo reconhecera como exigências éticas fundamentais -, essencialmente sob dois aspectos que derivam igualmente da primazia atribuída ao mercado: possibilidade de escolher o próprio estado social (profissão, lugar e modo de vida, relações etc.), assim como os bens e os serviços possuídos ou consumidos (Boltanski; Chiapello, 2009, p. 424-25).

Contudo, se o capitalismo moderno possibilitou essa liberdade, Weber destacou, por outro lado, que:

Apenas na base do trabalho livre pode haver cálculo racional de capitais, ou seja, quando, devido à existência de trabalhadores que se oferecerem formalmente de modo voluntário - mas de fato compelidos pelo chicote da fome -, é possível calcular prévia e exatamente os custos dos produtos com base em unidades de tarefas (Weber, 2006, p. 17).

É oportuno não esquecer que maneiras tidas como tradicionais do trabalho continuam a sobreviver e recriar-se dentro da sociedade moderna, compondo-a de singularidades, seja ao manter várias de suas dinâmi- 
Sociologias, Porto Alegre, ano 17, no 38, jan/abr 2015, p. 192-220

cas socioculturais e ambientais com base em suas autonomias possíveis (Wanderley, 2009), seja reproduzindo processos cada vez mais intensos de subordinação aos ritmos do capitalismo moderno (Mello, 1985).

Entendo que haja - na sociedade do trabalho pesqueira - uma semelhança (não a mesma coisa, porque são épocas bastante distintas) com as corporações de ofício mencionadas por Robert Castel (2005, p. 152), quando ele escreveu que, assim, essa organização do trabalho não permite o desenvolvimento de um processo de acumulação capitalista. No caso da pesca artesanal de Suape, o processo de acumulação não se dá internamente ao universo dos próprios pescadores, mas é claro que ela existe para outros sujeitos sociais que se apropriam do comércio de pescadores, por exemplo, como destacamos.

Deter barco individualmente (ou coletivamente pela companha) e, principalmente, o domínio de seu saber-fazer opõe-se à opressão, para os pescadores: Você trabalha no que é seu e ninguém te domina. Você vai quando quer em seu trabalho (Seu Gidinha, pescador mestre, 70 anos).

De fato, há, na pesca, uma identidade ineliminável entre trabalho e capital, que justifica o ninguém te domina (Seu Gidinha). Aqui, guardadas as diferenças sócio-históricas, não há um isolamento entre "o caracol e sua concha", com a conversão desses elementos em capital, como escreveu Karl Marx, sobre os artífices, em O capital.

Em geral, o trabalhador e seus meios de produção permaneciam indissoluvelmente unidos, como o caracol e sua concha, e assim faltava a base principal da manufatura, a separação do trabalhador de seus meios de produção e a conversão desses meios em capital (Marx, Livro 1, vol. I, 1982, p. 411).

Outro aspecto interessante a ser observado é a oposição feita pelos pescadores entre emprego e trabalho, pois aquele significa obrigação, sujeição e cativeiro e o trabalho da pesca liberdade. 
Sociologias, Porto Alegre, ano 17, no 38, jan/abr 2015, p. 192-220

Éo trabalho quem guarda minha liberdade. Não sou obrigado a ninguém (seu Neneu, pescador mestre, 67 anos).

Tá empregado é - mesmo que o cara não queira - tá preso. No trabalho da gente num tem isso não (Marco, pescador mestre, 32 anos)

A clareza contida na distinção entre emprego e trabalho, a partir das falas de seu Neneu e Marco, põe o trabalho como elemento central de uma vida livre, de sociabilidade singular, que se ancora na práxis produtiva e em um tipo mais autônomo de gestão do tempo por parte desses homens.

Em certo sentido, e guardadas as proporções, há aqui uma questão relevante, que necessita ser mais bem compreendida. Para tanto, penso que isso possa ser problematizado, em termos sociológicos, do seguinte modo: a noção que os pescadores têm de emprego liga-se à categoria labor (labour) na qualidade de subordinação e prisão da força de trabalho -, e a de trabalho da pesca liga-se à liberdade, criação, fim em si mesmo, ou seja, work.

O trabalho entendido como work, seria expressão de uma atividade genérico-social, voltada para a reprodução social de valores de uso, sendo por isso o momento da predominância do trabalho concreto. Em contrapartida, ao usar o termo labour, a ênfase se volta para as atividades estranhadas e feitichizadas, que configuram o trabalho assalariado [grifos do autor] (Antunes, 2005, p. 74).

Acerca disso, aludiu Heller (1994, p. 120): Se um produto não satisfaz nenhuma necessidade social ou é fabricado em um tempo de trabalho superior ao socialmente necessário, não se pode falar em work e sim de labour [tradução minha]. O que está, acima de tudo, contido nessa oposição de sujeição, obrigação e cativo, frente à noção de liberto, é o fato de os pescadores disporem de sua força de trabalho, na forma do uso do tempo e do seu corpo, diretamente. 
Esse é um fenômeno sócio-histórico quase universal em áreas rurais do Brasil, pois é comum encontrar definições vindas de camponeses, caiçaras e/ou pescadores diante de formas de trabalho compulsório tanto do passado como no presente (Diegues, 2004; Mourão, 2003), opondo as noções de cativo e liberto, sujeç̧ão e autonomia, o que faz com que os pescadores de Suape não sejam únicos na construção desse paralelo. Por exemplo, Afrânio Garcia Jr (1989), ao estudar camponeses nordestinos, mostrou que essa representação também é muito viva e presente no imaginário social desses homens:

Sujeição pode, assim, designar tanto a subordinação dos membros da unidade doméstica, quanto à subordinação dos produtos da atividade doméstica. Estas dimensões não são, contudo, equivalentes, pois é a subordinação dos indivíduos da unidade doméstica, do uso de seus corpos e de seu tempo útil, a mais ressentida como sujeição [grifos do autor] (Idem, p. 57-58).

Garcia Jr, em pesquisa anterior acerca de camponeses pernambucanos em áreas de plantation, foi em direção similar, quando revelou as representações e definições que esses trabalhadores faziam sobre os termos obrigação e sujeição, os quais passam também pela subordinação do produto do trabalho e dos sentidos humanos.

Na área estudada, os deveres dos moradores são especificados pelas categorias sujeição e obrigação. A sujeição se refere à obrigatoriedade de trabalhar para o grande proprietário de terra, sob as ordens deste, segundo uma periodicidade dada, submetendo-se ao pagamento que o grande proprietário se dispuser a oferecer. A obrigação refere-se aos deveres quanto ao destino da produção própria à unidade doméstica do morador, seja de lavoura, seja de animais. Ambas as categorias significam limitações quanto à livre disposição da força de trabalho da unidade familiar e/ou do produto por ela obtido [grifos do autor] (Garcia Jr, 1983, p. 60). 
Caminhando na mesma direção, ao refletir sobre o caso dos operários do açúcar também em Pernambuco, Lopes (1976) concluiu que o cativeiro liga-se à não autonomia de uso do tempo, especialmente o que seria destinado ao período em que estariam livres: $O$ cativeiro atual dos operários é o chamado da administração da usina na casa dos operários, no seu tempo livre, para ele comparecer à usina para trabalhar em serviço de "emergência" [grifo do autor] (idem, p. 137).

Então, sobre a oposição entre libertos e sujeitos emergiu, nas representações e práticas dos trabalhadores rurais, a seguinte síntese: [...] libertos, aqueles que dispõem de seu próprio tempo e dos membros de suas unidades domésticas, e sujeitos, aqueles cujo tempo é controlado por um patrão ou têm obrigações estabelecidas com dada periodicidade [grifos do autor] (Garcia Jr, 1989, p. 52).

Fernando Mourão explicitou as heranças históricas do termo cativo no sudeste brasileiro, e como a pesca transformou-se em uma esfera antagônica a isso, em chão de autonomias possíveis, para muitos caiçaras em São Paulo.

O recurso da pesca permitia e acentuava a tendência para a autonomia do trabalho, cuja inalienabilidade representa para a cultura caiçara um ponto positivo, uma vez que, tradicionalmente, nas áreas rurais, em decorrência da herança da escravatura, as formas heterônomas de trabalho nem eram possíveis no quadro econômico da época, nem representavam uma inspiração da população local.

A pesca que, nessa altura, "animou a juventude", permitiu que "não necessitasse de ser empregado" - "quem é empregado é sujeito" - afirmou-nos um velho pescador, e para um antigo morador de Pedrinhas, na I/ha Comprida, seus antepassados já aí viviam, "nunca passaram para o continente porque lá trabalhavam os negros em cativeiro e agora as terras foram vendidas a gente de fora" (Mourão, 2003, p. 139). 
De maneira geral, comandar o uso das próprias energias vitais humanas (pensamento e corpo) é situação balizadora do que é considerado livre. Nesse sentido, o corpo não é algo irrisório, mas decisivo na luta contra o domínio da sociabilidade do capital, que se sente, de fato, no controle ou não do tempo (Ramalho, 2011). Dominar o corpo passa pelo bom uso do tempo em favor das próprias vontades, de trabalho e de descanso. Perder um é desarfirmar o outro, pois eles são inseparáveis por se alimentarem mutuamente. Mais do que isso, a auto-exploração não é admitida e nem praticada nas embarcações por mim estudadas, posto que isso romperia com a moral da sociedade do trabalho, o uso positivo do corpo.

É claro que a pesca tem um ritmo próprio que a distingue dos trabaIhos classicamente capitalistas. Por conta da rotina do mar e dos pescados, fato que produz outra dinâmica de vida, e, devido a uma compreensão da sociedade fundada na cultura capitalista, acaba-se, muitas vezes, construindo uma leitura pejorativa sobre os pescadores, entendendo-os como avessos ao trabalho (Cunha, 1987) ou vagabundos. Na verdade, a hora da gente ir trabalhar é diferente porque depende do mar e dos peixes. Não se foge disso aqui (Jorge, pescador proeiro ${ }^{6}, 23$ anos). Sobre isso, gostaria de lembrar um trecho escrito por Manuel Correia de Andrade (2005, p. 139-140):

O praieiro dedica-se quase sempre à pesca, embora por processos ainda bastante rotineiros, com jangadas, viveiros ou currais. Ele é considerado em toda região como preguiçoso, como homem que gosta de pouco trabalho, o que é em parte exagero, uma fez que é muito dura a faina do pescador. Na verdade, se o regime de trabalho não tem a continuidade do trabalho em outras áreas, é porque depende muito do tempo e porque, na praia, a alimentação é facilmente encontrada nos mangues que ficam por trás das restingas. Aí são encontrados, em grande medida, os caranguejos, crustáceos que dão excelentes pratos.

\footnotetext{
${ }^{6}$ Pescador que atua na proa do barco, pescando sob a orientação do mestre. Embora o proeiro tenha também aguda habilidade, suas qualidades ainda não estão à altura da prática da mestrança, do saber-fazer do mestre.
} 
No que concerne à dependência dos pescadores em relação à natureza marinha, o historiador E. P. Thompson aludiu:

Os pescadores e os navegadores devem integrar as suas vidas com as marés. [...] A expressão operacional é "cuidar das marés": a padronização do tempo social no porto marítimo observa os ritmos do mar; e isso parece natural e compreensível para os pescadores ou navegadores: a compulsão é própria da natureza (Thompson, 1998, p. 271).

No uso do tempo livre e do trabalho, situa-se, para os pescadores, a razão de muitos os acusarem de preguiçosos.

O pescador só que ir pra maré quando acabou aquele dinheiro que ele ganhou, aí chamam ele de preguiçoso. Mas não é. Só que ele vai quando termina o dinheiro. Ele também não quer gastar o corpo. Aí chamam o cabra de preguiçoso (seu Gidinha, pescador mestre, 70 anos).

Há um profundo respeito pelas possibilidades da fruição sensível em princípios voltados à humanização da força de trabalho, que não deve submeter seus desígnios ao ritmo utilitário do capital. Por conta dessa utilidade humanizada, o pescador de Suape vai quando termina o dinheiro, quando se torna mais uma vez indispensável retornar às águas de acordo com suas próprias necessidades e liberdades de escolhas. Ademais, ele também não quer gastar o corpo (Seu Gidinha), impondo-lhe ritmos desumanizados que o levem à exaustão, à fadiga e à auto-depredação, na medida em que isso não condiz com seu valor simbólico e prática de vida. Ou seja, gastar o corpo, de acordo com os desígnios de sua conduta moral de vida, tem a ver com a gestão do seu próprio tempo de trabalho e lazer. De fato, ao não se enquadrar nos requisitos e critérios modernos, aí chamam o cabra de preguiçoso (seu Gidinha), de inútil ao não ser útil à moral instrumental de utilidade direta do trabalho para o capital.

Antonio Candido, em Parceiros do Rio Bonito, categorizou a lógica do caipira de lidar com o trabalho enquanto uma desnecessidade de trabalho. 
[...] devemos também apontar as determinantes econômicas e culturais de um fenômeno que não deve ser considerado vadiagem, mas desnecessidade de trabalhar, que é outra coisa e, no caso, mais importante para caracterizar a situação [grifo meu] (Candido, 2001, p. 111-112).

O descanso e o lazer - essas desnecessidades de trabalhar - só são vistos como desabonadores quando negam o trabalho da pesca e passam a ser um ato de irresponsabilidade, que leva a família à fome. Desnecessidade de trabalhar que é uma contrarracionalidade, uma maneira específica de gestão do próprio tempo, onde práticas materiais e imateriais presentes nas maneiras de viver, em [...] éticas e estéticas de vida que resistem a uma entrega à racionalidade do mundo dos negócios apregoa e vende, atribuindo a quem ela não adere a imagem do 'atraso' (Brandão, 2007, p. 57). Tornar-se irresponsável é romper com a ética do descanso, jogando o pescador na seara do que, de fato, para eles, é a preguiça, ao transformar a ação de quem a pratica em sinônimo de imoralidade, de falta de vergonha e de desrespeito.

O pescador que passar fome ou faz sua família passar ou ele tá doente ou tem é muita preguiça. Veja só, se ele nada tiver em casa, ele pode ir ainda no mangue e pro mar pegar uns aratus, uns peixinhos e colocar com um pouco de farinha. Já arrumou o que comer. O pescador pode não ser rico, mas fome não passa, não. Só se for preguiçoso (seu Luiz Augusto, pescador mestre, 66 anos).

O cara descansar é diferente do preguiçoso. O preguiçoso é o cabra safado que faz a sua família passar necessidade, por não querer trabalhar mais. O que descansa não; e ele tem suas responsabilidades sem ser cativo, porque escolhe suas horas de trabalhar e seu lazer. Ele [o pescador que descansa] é trabalhador e sabe fazer a sua hora; a hora das coisas, de ir pro mar e de bater uma bolinha sem dá satisfação a seu ninguém (Joaquim, pescador proeiro, 25 anos). 
O preguiçoso é o que confunde as coisas. Não quer trabalhar de jeito nenhum e faz a família passar necessidade, sem botar comida na mesa dos meninos e da sua mulher. O mar tem de tudo e o cara fazer isso, é preguiçoso e não tem moral (Marco, pescador mestre, 32 anos).

Emilio Willems (2003, p. 98) identificou o mesmo processo entre caiçaras, no final da década de 1940: Um homem que não pode abastecer sua família dentro dos limites da convenção local não é visto com bons olhos. Ademais, frisou o estudioso:

Os caiçaras podem passar dias e dias em completa inanição, sem se sentirem culpados de nenhum pecado ou de má conduta. O ócio deste tipo é normal na cultura caiçara e certamente não é sinônimo de preguiça. Um homem é considerado preguiçoso quando não consegue dar à sua família comida e roupa suficientes e quando ele a deixa a baixo do nível local aceito a esse respeito. [...] Comparando o regime de trabalho dos Ilhéus com o nosso, podemos dizer que o primeiro não envolve necessariamente o gasto de um esforço, mas sim uma concentração irregular de esforços gastos (Idem, p. 99).

Ter o corpo no tempo em que se acredita necessário e útil para o uso da força de trabalho é poder também dispor dele no instante em que se julga melhor descansar, repor as energias sensíveis, divertir-se, bater um papo, tomar cachaça, jogar um futebol ou uma partida de dominó e/ ou ficar em casa com os filhos e a esposa. Portanto, controlar o trabalho é estar, em contrapartida, em condições favoráveis de usar seus sentidos para momentos de lazer, pela desnecessidade do trabalho. Aqui, trabalho e vida não se apartam, não se estranham e não criam dicotomias, pois se integram como entes essenciais para que ambos possam existir de modo humanizado, de forma responsável, onde uma não pode usurpar a outra.

O pescador é livre, porque ele tá na beira da praia desarmado, descansando. Vai pra casa e tira seu cochilo. De madrugada, quando quer, tá de pé pra sair pro mar. Vai 
Sociologias, Porto Alegre, ano 17, no 38, jan/abr 2015, p. 192-220

quando é necessário. A gente não bate cartão pra ninguém (Conrado, pescador mestre, 39 anos).

Pelas bandas daqui, ao pescador não tem igual. Nós somos livres, porque decidimos a hora de descansar e de ir pro bote (Jorge, pescador proeiro, 23 anos).

O cabra trabalhou pra outro é cativo. O pescador não. Ele vai no dia que quer. Eu parei minhas coisas e pronto. Fico aqui e volto no dia que quero. Eu sou um cabra liberto (seu Luiz Augusto, pescador mestre, 66 anos).

Encontrar-se livre é ter no seu trabalho de pescaria a afirmação do seu tempo livre, isto é, tempo livre é igual a trabalho livre, porque a gente não bate o cartão pra ninguém e, dessa maneira, fica, quando deseja, descansando, olhando a praia, conversando ou vai pra casa e tira aquele cochilo (Conrado), no intuito de renovar as forças vitais e revelar que a vida não se exclui do trabalho ou este não é nenhum mal necessário para poder viver. É o pescador quem decide a hora de descansar e de ir pro bote (Jorge). Agora, o cabra trabalhou pra outro é cativo (seu Luiz) por prender seus sentidos humanos e não escolher, no momento em que quiser, ir descansar.

É claro que, segundo o pescador 'seu' Neneu, o tempo do pescador é o da maré, isto é, sua vontade deve encontrar-se em sintonia com o tempo da natureza e ele não pode deixar de compreender isso. Contudo, como frisou o pescador Joaquim, a água não me coloca cabresto, como faz um patrão com base em profundas desigualdades e hierarquias socioeconômicas. Na pesca, [...] os espaços da vida e do trabalho ainda são, em larga medida, os da própria natureza (Brandão, 2007, p. 51).

Há um entrecruzamento indivisível, porque vida e trabalho são partes integrantes da condição liberta do pescador, pelo uso mais autônomo, inclusive, da esfera sensitiva, cuja síntese permite a concretização do sentimento de que o pescador é livre, por ser liberto seu trabalho e sua vida 
e também o ambiente em que trabalha (o mar). Na realidade, para os pescadores, o trabalho é um fim em si mesmo, lócus de realização prática da liberdade possível diante das injunções diretas do capital e, também, onde pode buscar-se o chão da verdadeira identidade liberta, da necessidade e desnecessidade do trabalho.

Há aqui uma moral do trabalho que não se coaduna com a moral burguesa do trabalho, visto que esta se encontra a serviço do valor de troca e aquela do valor de uso. Elas, portanto, são incompatíveis enquanto projetos existenciais. Por isso, a moral burguesa desqualifica e/ou tenta suprimir a moral do trabalho pesqueiro artesanal.

O sentir dos sentidos humanos e a força de trabalho dos pescadores artesanais resistem em serem consumidos como meras mercadorias, por se encontrarem regulados pela ética de uma existência pesqueira e a ideologia da sua sociedade do trabalho artesanal, corporativa, que é refratária à obrigação, à sujeição e à condição de cativo. Não é por acaso que Paul Lafargue, ao analisar e denunciar a supremacia da moral burguesa do trabalho e a vitória do trabalho morto (capital, máquina, tecnologia) sobre o vivo (saber-fazer humano) nos idos de 1883, escreveu:

Para que a concorrência entre homem e a máquina tomasse livre curso, os proletários aboliram as sábias leis que limitavam o trabalho dos artesãos das antigas corporações; suprimiram os feriados. Porque os produtores dessa época trabaIhavam apenas cinco dias da semana, julgavam eles então, conforme dizem os economistas mentirosos, que viviam só de sombra e de água fresca? Ora vamos! Eles tinham tempo livre para gozar as alegrias da terra, para fazer amor, para se divertir, para se banquetear em honra do alegre deus do Fazer Nada (Lafargue, 2003, p. 47). 
Lafargue viu, então, na internalização do dogma da moral burguesa do trabalho, a grande negação do operariado, a essência de sua expropriação física e mental, sua escravidão aos desígnios das vontades empresariais:

Se, extirpando do seu coração o vício que a domina e avilta a sua natureza, a classe operária se erguesse com sua força terrível, não para reclamar os Direitos do Homem, que não são senão os direitos da exploração capitalista, não para reclamar o Direito ao Trabalho, que não é senão o direito à miséria, mas para forjar uma lei de bronze que proibisse todos os homens de trabalhar mais de três horas por dia, a Terra, a velha Terra, tremendo de alegria, sentiria nela surgir um novo universo... Mas como pedir a um proletário corrompido pela moral capitalista uma decisão virial? [...] há um século o trabalho forçado quebra seus ossos, fere suas carnes, destrói seus nervos: há um século a fome torce suas entranhas e alucina seu cérebro!... Ó Preguiça, tem piedade de nossa longa miséria! Ó Preguiça, mãe das artes e das nobres virtudes, seja o bálsamo das angústias humanas! (Lafargue, 2003, p.75-77).

Segundo Thompson (1998), na sociedade capitalista do tipo madura, todo o tempo deve ser consumido, negociado, utilizado; é uma ofensa que a força de trabalho meramente 'passe o tempo' [grifo do autor] (p. 298), porque ela deve estar produzindo divisas, riquezas, sobre-trabalho para o capitalista. De fato, as sociabilidades genuinamente capitalistas, são marcadas pela administração do tempo e por uma clara demarcação entre o 'trabalho' e a 'vida' (p. 300), donde, realizar-se enquanto homem ou mulher feliz, só fora do trabalho, para muitos.

Nos Manuscritos econômico-filosóficos, Marx problematizou acerca disso:

Em que consiste então a exteriorização (Entäusserung) do trabalhador?

Primeiro, que o trabalho é externo (äusserlich) ao trabalhador, isto é, não pertence ao seu ser, que ele não se afirma, portanto, em seu trabalho, mas nega-se nele, que não se sen- 
te bem, mas infeliz, que não desenvolve nenhuma energia física e espiritual livre, mas mortifica sua physis e arruina o seu espírito. O trabalhador só se sente, por conseguinte e em primeiro lugar, junto a si [quando] fora do trabalho e fora de si [quando] no trabalho. Está em casa quando não trabalha e, quando trabalha, não está em casa. O seu trabalho não é portanto voluntário, mas forçado, trabalho obrigatório. $O$ trabalho não é, por isso, a satisfação de uma carência, mas somente um meio para satisfazer necessidades fora dele [grifos do autor] (Marx, 2004, p. 82-83).

A sociedade do trabalho da pesca, que produz o artista pescador ao ser reproduzida por ele, fez do trabalho espaço central de uma existência que encontra no fazer produtivo também sua realização humana, por mais simples que seja, porque pensar e apreciar o próprio trabalho é algo que o capital pode ter banido da fábrica, mas não conseguiu banir da vida do trabalhador (Martins, 2008, p. 57). Como se nota, a concepção de trabalho do trabalhador é sociológica e antropologicamente muito mais rica do que a concepção que chega às análises sociológicas e políticas (idem, p. 58). De fato, a organização societária dos pescadores expressa uma cultura do trabalho irredenta, que mesmo não conseguindo assumir características políticas (e ela não tem isso - um ethos polítiCo - no caso dos pescadores de Suape), construiu uma dinâmica de vida e de trabalho que não podem ser compreendidas como semelhantes às condutas moral do moderno capitalismo.

Em suma, a cultura pesqueira do trabalho, sua ideologia e seu sentimento de corporação têm no espaço produtivo seu território privilegiado onde reverbera sentimentos libertos, de humanização das águas, de sublevações às possibilidades de domínio de sua vida e de seu trabalho pelos valores mercantis. Então, é a arte da pesca o lócus do irredentismo, da resistência de um mundo do trabalho que se quer e, acima de tudo, se sente mais importante que o capital [grifos do autor] (Ramalho, 2007, p. 118-119). 
Nesses termos, a utilidade humana (do corpo e da mente) assenta-se num projeto de liberdade, que é um valor, um modo de vida, uma contrarracionalidade. Por isso, a frase a seguir ganha significado valioso para desnudar o que representa isso, concretamente: Nossa mente e o corpo andam ajuntados pra gente ficar livre (Gildo, pescador proeiro, 45 anos).

Ser liberto não é remeter a mente para além de uma suposta "prisão carnal" ou negar o trabalho pelo lazer, mas, ao contrário; é unir os sentidos humanos à consciência e aos laços entre vida e trabalho, que andam ajuntados pra gente ficar livre (Gildo) do fracionamento e da separação entre planejar e executar, da oposição entre descanso e trabalho e da perda do corpo e da mente para o mundo capitalista, ao transformar seu trabalho em labor ou vida e trabalho em entes opostos, antônimos. Uma relação humanizada do ser humano com a sua corporeidade desdobra-se num metabolismo social também humanizado com o meio ambiente, visto que sua autoexploração ocasionaria em aumento de captura dos pescados, uma sobrepesca. Nesse sentido, o cotidiano dos trabalhadores marítimos externaliza uma ética, que pode ser traduzida numa estetização da vida: Usar muito o corpo é ruim. Quando a gente descansa, nós deixa o mar lá descansando também (Genildo, pescador mestre, 35 anos).

Evidencia-se, então, uma relação integrada e sofisticada em que a exploração de si e dos outros leva consigo rebatimentos negativos para o metabolismo do ser humano com o meio ambiente marinho. Preservar o sensível orgânico (sentidos humanos) é, ao mesmo tempo, preservar o sensível inorgânico (a natureza).

Tempo livre e tempo de trabalho conformam-se num tipo de moral pesqueira que molda a relação entre os próprios pescadores, de gestão de seu tempo de trabalho e lazer e desses homens com o ambiente marinho, com os pescados, forjando práticas societárias repletas de humanização e de sutis resistências à conduta de vida genuinamente capitalista, 
que se celebram, nos ritmos imanentes da cultura pesqueira artesanal, a necessidade e desnecessidade do trabalho.

\section{Conclusão}

Há entre os pescadores do mar alto da praia de Suape uma sociedade do trabalho, que produz uma moral produtiva e do tempo livre integradas, criadoras de uma conduta de vida que não se coaduna ao ethos do capitalismo. Nessa sociedade, a vida enraíza-se no trabalho assim como o trabalho funda-se numa vida repleta de sociabilidade cheia da desnecessidade de trabalhar e da necessidade autônoma de se trabalhar, fatores que fazem dos momentos de lazer algo tão importante quanto ir à água para efetivar o saber-fazer pesqueiro artesanal. Assim, o tempo livre não sobreviveria sem o tempo do trabalho e vice-versa. Tais tempos são elos indissolúveis para os pescadores, que se expressam numa gestão peculiar de sua vida, trabalho e lazer.

O trabalho da pesca e a manutenção de sua tradição corporativa guardam a liberdade do pescador e, com isso, a possibilidade dele dispor do tempo livre, de contar com suas energias vitais (físicas e mentais) no momento em que julgar necessário tê-las a sua disposição, para ir ao mar ou ficar na praia ou em casa com os amigos e parentes.

Embora a resistência não se faça no plano político em Suape, a cultura do trabalho pesqueiro tem em si a qualidade de lugar, para os homens que vivem da pesca artesanal, da realização de uma vida não cativa, obrigada ou sujeita. Cultura do trabalho essa que cultiva atos de irredentismo societário e que transformou a pesca em território da liberdade ou, no mínimo, num caminho promissor para concretizar projetos de autonomia possíveis de vida, cuja luz ilumina o presente e serve de alimento ao futuro, para esses homens e seus familiares. 
Cristiano Wellington Noberto Ramalho - Professor Adjunto de Sociologia do Departamento de Ciências Sociais (DECISO) da Universidade Federal Rural de Pernambuco (UFRPE), coordenador do Grupo de Estudos Mares, Ambientes e Ruralidades (GEMARES) e professor colaborador do Programa de Pós-Graduação em Desenvolvimento e Meio Ambiente (PRODEMA) da Universidade Federal de Sergipe (UFS).

$\triangle$ cristiano.ramalho@yahoo.com.br

\section{Referências}

1. ANDRADE, Manuel Correia de. A terra e o homem no Nordeste: contribuições ao estudo da questão agrária no Nordeste. $7^{a}$ edição. São Paulo: Cortez, 2005.

2. ANTUNES, Ricardo. O caracol e sua concha: ensaios sobre a nova morfologia do trabalho. São Paulo: Boitempo, 2005.

3. BIDET, J. Sur lês raisons d'être de L'idêologie (les rapports sociaux dans le secteur de la pêche). La Pensée, [S. 1.], no. 174, 1974.

4. BOIVIN, Mauricio; ROSATO, Ana. Pesca y transformaciones socioeconómicas a principio del siglo XXI: un análisis etnográfico de los pescadores del delta entrerriano, Argentina. In: ALCALÁ, Graciela (Org.). Pescadores en América Latina y el Caribe: espacio, población, producción y política. Vol. II. México: Facultad de Ciencias de la Universidad Nacional Autónoma de México, 2011, p. 185-211.

5. BOLTANSKI, Luc; CHIAPELLO, Ève. O novo espírito do capitalismo. São Paulo: Editora WMF/Martins Fontes, 2009.

6. BRANDÃO, Carlos Rodrigues. Tempos e espaços nos mundos rurais do Brasil. Revista Ruris - CERES - UNICAMP, Campinas, vol. 1, n. 2, mar. 2007, p. 37-64.

7. BRITTO, Rosyan Campos de Caldas. Modernidade e tradição: construção da identidade social dos pescadores do Arraial do Cabo-RJ. Niterói: Eduff, 1999.

8. CANDIDO, Antonio. Os parceiros do Rio Bonito. São Paulo: Duas Cidades; Edições 34, 2001.

9. CASTEL, Robert. As metamorfoses da questão social. $5^{\text {a }}$ edição. Petrópolis: Vozes, 2005.

10. CUNHA, Lúcia Helena de Oliveira. Entre o mar e a terra: tempo e espaço na pesca em Barra da Lagoa. 1987. 244 f. Dissertação (Mestrado em Antropologia) Pontifícia Universidade Católica de São Paulo, São Paulo. 
Sociologias, Porto Alegre, ano 17, no 38, jan/abr 2015, p. 192-220

11. DIEGUES, Antonio Carlos. Repensando e recriando as formas de apropriação comum dos recursos naturais. In: DIEGUES, Antonio Carlos; MOREIRA, André de Castro (Org.). Espaços e recursos naturais de uso comum. São Paulo: NUPAUB/ USP, 2001, p. 97-124.

12. DIEGUES, Antonio Carlos. A pesca construindo sociedades. São Paulo: Nupaub-USP, 2004.

13. GAC, Antonio J. Zamora. Pescadores artesanales de Valparaíso, Chile: subsistema econômico "sociedad a la parte" y crisis en .a pesquería de La merluza común. In: ALCALÁ, Graciela (Org.). Pescadores en América Latina y el Caribe: espacio, población, producción y política. Vol. II. México: Facultad de Ciencias de la Universidad Nacional Autónoma de México, 2011, p. 81-113.

14. GARCIA Jr, Afrânio. Terra de trabalho: trabalho familiar de pequenos produtores. Rio de Janeiro: Paz e Terra, 1983.

15. GARCIA Jr, Afrânio. O sul: caminho do roçado - estratégias de reprodução camponesa e transformação social. São Paulo: Marco Zero; Brasília: Editora da UnB/MCT-CNPq, 1989.

16. HELLER, Agnes. Sociologia de la vida cotidiana. 4a edição. Barcelona: Ediciones Península, 1994.

17. LAFARGUE, Paul. O direito à preguiça. São Paulo: Editora Claridade, 2003.

18. LOPES, José Sérgio Leite. O vapor do diabo: o trabalho dos operários do açúcar. Rio de Janeiro: Paz e Terra, 1976.

19. MARX, Karl. O capital. Livro I, Vol. 1. 8a edição. São Paulo: Difel, 1982.

20. MARX, Karl. Formações econômicas pré-capitalistas. $6^{a}$. edição. São Paulo: Paz e Terra, 1991.

21. MARX, Karl . Manuscritos econômico-filosóficos. São Paulo: Boitempo, 2004.

22. MARTINS, José de Souza. A aparição do demônio na fábrica: origens sociais do Eu dividido no subúrbio operário. São Paulo: Editora 34, 2008.

23. MELLO, Alex Fiúza. A pesca sob o capital: a tecnologia a serviço da dominação. Belém: Editora da UFPA, 1985.

24. MOURÃO, Fernando A. Os pescadores do litoral sul de São Paulo. São Paulo: Hucitec/Nupaub/Cec, 2003.

25. PESSANHA, Elina Gonçalves da Fonte. Os companheiros: trabalho na pesca de Itaipu. Niterói: Eduff, 2003. 
26. RAMALHO, Cristiano Wellington Noberto. "Ah, esse povo do mar!": um estudo sobre trabalho e pertencimento na pesca artesanal pernambucana. São Paulo: Editora Polis; Campinas: Ceres, 2006.

27. RAMALHO, Cristiano Wellington Noberto. Embarcadiços do encantamento: trabalho como arte, estética e liberdade na pesca artesanal de Suape-PE. 2007. 301 f. Tese (Doutorado em Ciências Sociais) - Instituto de Filosofia e Ciências Humanas, Universidade Estadual de Campinas, Campinas.

28. RAMALHO, Cristiano Wellington Noberto. O sentir dos sentidos dos pescadores artesanais. Revista de Antropologia - USP, São Paulo, vol. 54, n. 1, p. 315-352, jan/junho, 2011.

29. RAMALHO, Cristiano Wellington Noberto. Sentimento de corporação, cultura do trabalho e conhecimento patrimonial pesqueiro: expressões socioculturais da pesca artesanal. Revista de Ciências Sociais, Fortaleza, v. 43, n. 1, p. 8-27, jan./jun. 2012.

30. SOUZA, Jessé. Os batalhadores brasileiros: nova classe média ou nova classe trabalhadora? Belo Horizonte: Editora UFMG, 2010.

31. THOMPSON, E. P. Costumes em comum: estudos sobre a cultura popular tradicional. São Paulo: Companhia das Letras, 1998.

32. WANDERLEY, Maria de Nazareth Baudel. O mundo rural como espaço de vida. Porto Alegre: Editora da UFRGS, 2009.

33. WILLEMS, Emilio. A ilha de Búzios: uma comunidade caiçara no Sul do Brasil. São Paulo: Hucitec; Nupaub/CEC, 2003.

34. WEBER, Max. A ética protestante e o "espírito" do capitalismo. São Paulo: Companhia das Letras, 2004.

35. WEBER, Max. A gênese do capitalismo moderno. São Paulo: Ática, 2006.

36. WOLF, Eric. Sociedades camponesas. Rio de Janeiro: Zahar Editores, 1970.

37. WOLF, Eric. Tipos de campesinato latino-americano: uma discussão preliminar. In: FELDMAN-BIANCO, Bela; RIBEIRO, Gustavo Lins (Orgs.). Antropologia e poder. Campinas: Editora da Unicamp; Brasília: UnB, 2003, p. 117-144.

Recebido em: 13/02/2014

Aceite Final: 07/10/2014 